\title{
Deleuze, art and social work
}

\author{
Abstract \\ This article outlines the value of Deleuze's philosophy to social work in offering a different \\ understanding of the constitution of reality and being human and the importance of the visual by \\ way of artistic and craft activities. The key concepts derived from Deleuze's work and outlined in the \\ article concern the idea of the 'virtual' as relevant to the concept of 'a life' and 'difference and \\ repetition' as a way of conceptualising an anti-essentialist post-modern view of identity as \\ fragmented, but dynamic. In other words partaking of chaotic, but also creative potential. This \\ conceptual isation of life allows to think about all lives, even 'difficult' ones, as potentially creatively \\ undetermined in the future, rather than just pathologically predetermined by the past. Arts and \\ crafts are seen as having the power to provoke and soothe, allowing a process of discovery of what \\ the material and the person might both become in the doing. Thus the article offers an ontological \\ grounding validating not just arts and crafts, experiential learning and apprenticeship models as \\ essential to social work practice and training at a time when these might be driven out by evidence \\ based paradigms ad budget cuts.
}

\section{Keywords}

Deleuze, visual, imagination, art, crafts, social work, ontology, epistemology 


\section{Introduction}

The argument put forward in this article is that Deleuze's philosophy offers a way of understanding how visual imagination as part of art and craft activities opens possibilities for re-framing one's experiences and working with problems. In order to validate and explicate this claim it introduces some of Deleuze's key ideas to offer a particular ontological and epistemological grounding for the importance of visual arts and crafts in the practice of social work. This is important in the light of evidence-based and scientific/positivistic models having restricted what is valued and given time, in a period of unprecedented cuts to social care budgets.

For those unfamiliar with the terms ontology and epistemology, ontology refers to the 'nature of being', or to put it another way what we believe the nature of reality to be, while epistemology concerns the study and practices that might arise from what we believe that nature of being and reality to be. Deleuze's philosophical framework offers a very different, often very abstract way of thinking about the nature of being and of reality, more concerned with understanding change and process, than with outcomes. Simply put, process is about how one lives in the world, how one is affected by one's context and surroundings and how one affects them, in other words it is about the more fluid aspects of life, mostly happening below the level of consciousness.

While there is literature about the value of arts and crafts in the field of Social Work (see most recently in this journal Trevelyan et al., 2014; Tudor et al., 2015; Moxley and Feen, 2015), my aim here is to outline what the philosophy of Deleuze offers to an understanding of why arts and crafts need to be valued in both the practice and the training of social workers. It is noted by many authors (Bell, 2012, gives an excellent overview) that ontological issues have been relatively neglected and that this gap creates inconsistency between ontological foundations, epistemology, ethical aims of the profession and mainstream practice. This article therefore aims to make a small 
contribution to this needed development of 'post-conventional' (Bell, 2012) ontological and theoretical grounding in the field.

To do this the article starts with a Deleuzian view on the nature of being human, which is then followed by a reflexive narrative to explicate, ground and exemplify what follows from such ontological tenets. As often those entrusted to the social care profession are those suffering what Goffman (2009) would term 'spoiled identity', identity, seen as dynamic and embodied, open to contradictions and disorder (Deleuze 2004; 2005; Deleuze and Guattari, 1999), is the starting point. This allows the introduction of how difference and repetition are conceptualised as key to it in Deleuze's (2004) work. These concepts are also later related to artistic practices and are embedded in a wider understanding of life as composed of a duality. This duality is not one of nature and culture or mind and body, rather Deleuze (following Bergson) proposes that alongside what is actualised in our embodied, historical existence another realm is continuously present, while being out of sight. The term used to denote this less visible, beneath the surface, but real domain is the 'virtual' (not to be confused with virtual as in virtual reality). This formulation acknowledges mostly unseen forces and tensions in our lives that lead to actual events, but by doing so restrict the potential, that all of us have, to respond to them creatively. The argument being developed is that arts and crafts give access to that realm and its potential, by freeing up imagination, while giving expression to the tensions and conflicts underlying actual problems, creating the opportunity to change our relation to them and move forward in a new way. Arts and craft activities have the capacity to provoke and soothe, to open up a process of discovery of what the material and the person might both become in the doing.

This framework offers an alternative perspective to the dominant neo-liberal, evidence based and medicalised discourses. While the value of art is not a new idea, a positivist and reductive paradigm allied to neo-liberal policies has meant that this aspect of practice, when and if it happens, is most often unsupported by institutional structures (Moxley and Feen, 2015). 


\section{Identity, difference and repetition and a bit of contextual framing in relation to social work}

The word identity gives us a clue to what is normally regarded as key to it, namely being 'idem'-Latin for same- over time. In Deleuze's and much post-modern theory no such thing is possible in a literal sense and most of us can acknowledge in a common sense way that whol am now cannot be quite the same as who I was many years ago, yet most of us have a sense of continuity under normal circumstances. Our bodies give an example of that: they are continually changing, cell renewal means that in reality our bodies are never the same. The paradox is that in spite of this, we are recognisable to ourselves and others, unless some majorly traumatic event occurs or we choose to change our appearance in major ways. Difference and repetition, as Deleuze (2004) points out, are not oppositional binaries, but relationally implicated with each other: for things to stay the same, continuous renewal is required. Our bodies as well as our identity over time rely on this relation between difference and repetition for the experience of continuity. In Deleuze's (2004) view, repetition always involves difference, it is never repetition of the same. What we repeat is the overall pattern of relations that make us who we are, while the elements that are in relation are always in flux. Art follows the same process: we use different materials to express our perceptions and experiences. The artistic production is not the object, just as the map is not the territory, but a different re-presentation (used in the sense of presenting anew) of our encounter with it through a different medium. This I hope will become clearer as I expand on the theoretical frame with examples in the following sections of the article.

While the continuous process of change, both inner and outer, ensures our survival, it is the aspect we are least aware of. It is the one we tend to take for granted, prizing the sameness that it is seemingly in service to. There is a hierarchical ordering here and an oppositional stance. The sameness (you don't look a day older!) is seen as an aspect of health, while pathologising has its field day in its disruptions, making use of the relative ubiquity of some aspects of change and 
development by normalising them, while highlighting others as anomalies to be got rid of, more often than understood. This is where people with dementia, intellectual disabilities and/or traumatised and/or disordered lives show us aspects of being human with a problematic social and policy history. We have moved away from the more severe manifestations of not wanting to see them or be reminded of them, by no longer locking people up in segregate d institutions. Yet having attempted to rectify the situation through care in the community and other policies, other new and different problems have taken the place of old ones. In extreme cases the learning disabled or mentally unwell requiring acute intervention are often wrongfully placed in secure institutions or prisons that have replaced the old institutions (segregated residential/ asylums). Dealing with less extreme difference, on the other hand, relies on over-optimistic faith in the capacities of individuals, families and (fast disintegrating) communities to care in an often culturally and materially impoverished environment. Thus social and other care work these days is not only having to be outcome and bio-medically driven, but fragmented and often reduced to the provision of statutory duties. Bell (2012) and others argue that the inconsistency between social work's modernist ontological foundations and many of social work's epistemological concepts, such as anti -oppressive and critical approaches, represents a major contradiction in the conceptual isation of the profession's philosophical base. Newapproaches are needed.

Adopting a Deleuzian view, identity is about a dynamic relation between difference and sameness, open to change and 'becoming' and encompassing disordered states of mind as part of everyone's make-up. These are seen as potentially creative, rather than just dysfunctional. This allows it to chime with the ethical concerns of social justice, notions of equality and non-discriminatory practices that have animated the profession. Art and craft allow for that creativity to be accessed. I have mentioned a particular kind of duality at the heart of Deleuze's philosophy. This is expressed in synthesis in Deleuze's last essay A Life (2005).

\section{'A life'}


The Deleuzian concept of ' $a$ life' can be understood as equivalent to the 'virtual' in relation to an individual. 'A life' is unique, 'impersonal and yet singular' (Deleuze, 2005: 8-9). It does not require a conscious process of individual isation and can never be completely specified. It is something that underlies 'the life' of the individual, it is the hidden, though real realm of forces and tensions that give rise to 'their' life. It is 'pure immanence', that is something underlying, deeply implicated in all of reality (Williams in Parr, 2005: 125-127), generative of, yet not superior too, actual conditions of existence. It is something we might be able to connect to more closely in significant moments of intensity.

$A$ life is everywhere, in all the moments that a given living subject goes through and that are measured by given living objects: an immanent life carrying with it the events and singularities that are merely actualized in subjects and objects. [...] The singularities and the events that constitute $a$ life coexist with the accidents of the life that corresponds to it, but they are neither grouped nor divided in the same way. (Deleuze, 2005: 29-30)

His essay Immanence: A Life from which the above quote is derived is his last piece of writing, some would call it a sort of testament (Deleuze, 2005: 20); short and hard to decipher without prior exposure to his work, it gives us a final synthesis of what his work tries to open up for us: a different way of thinking about the world, that encompasses both the material and actual world we live in and its real, but not actualised, generative conditions. Let me give you an example: a complex combination of push/pull factors is usually involved in migration, these factors range from environmental, personal as well as political. When the tensions of existence in one's place of origin or residence become too intense, the result is migration. That is the actual event, but those tensions have generated it and only some aspects may be readily identified. Others remain beneath the surface unknown to the migrant like me (I was born and grew up in Italy) : I only became fully aware of a trajectory initiated three generations back through an ethnographicjourney back to my Italian roots. The conditions for my coming to England were far more complex than I had known till then. 
My life is here in England, 'alife' includes all the influences I absorbed in Italy and still link me to that place. The general realm of these conditions is what is meant by the 'virtual': a transcendental realm of interconnections, tensions and relations of forces, encompassing all of existence: it is where the potentiality of the world resides, its variety and indeterminacy, which is continuously transformed into our actual living. As such it encompasses the natural and environmental forces that underlie the world we live in, as well as the unconscious processes of the human mind.

'A life', rather than 'the life of' or 'my life' or 'my identity' indicates both a generality and a specificity, which is not about possession, as in 'my life', or judgement (Deleuze, 2005). We cannot refrain from judgement about having a good or a bad life, we are so used to it. Our judgements are often superficial and based on repertoires of categories, which those less familiar with them would neither necessarily agree with nor recognise themselves within. The idea of 'poverty', for example, is not something non-modern societies would recognise about themselves, it is an etic concept, i.e. a concept belonging to outsiders to that context. Take the idea of victimhood and dependency. Why does benefit fraud so enrage public opinion? Of course there is more than one answer (see author's own, 2012 for a different one), but given its very low incidence (0.9\%) and low impact in the grand scheme of things, what may be one of its most effective powers to offend is that it puts two fingers up to the idea of the dispossessed as poorvictims. It turns the tables on the accustomed, 'pro per' order of things; it transgresses the emotional economy of power. Choosing a life on the streets is something few 'housed minds' can appreciate as a choice. It is rather conceived as a matter of personal irresponsibility, rather than a reasonable response to conditions that make it the best one might be able to aspire to at a particular time or on a more permanent basis (see Scanlon and Adlam, 2006). The possibility that such choice may be actually about a life that has kept closer to chaos and indeterminacy in a positive way and learned to live with problems as best it can, does not often get taken seriously. Yet this is what Deleuze would advocate: the art and craft of living with problems, rather than the resolution or elimination of them. This does not of course mean we should just stop thinking about the conditions that have made that the best option for some, though 
it takes us away from stigmatising and thinking of such situations in a reductive and individualised way.

It also offers hope, something much needed in any work that involve s exposure to people in distress and in need of care. It offers a positive view: 'a life' is always in the making (ibid: 13-14). This is true for all of us and all of us partake of moments or events that lead us to disordered states, what Deleuze would term 'pre-subjective delirium' and 'pre-individual singularity'. These terms are used to denote a zone or plane of indeterminacy in any person's make up. These terms are suggestive of the chaotic, the personality disordered, the discontinuous or irrational. This is often what disenfranchised, autistic, mentally unstable persons and, according to Deleuze, children show us: they are singular, we could not confuse them with someone else, yet they are not necessarily coherent and self-aware. Often they are more capable of intensity and passion, than supposedly better adjusted, more ordered characters. Could this be an indication of a closer relation to 'a life', to the 'virtual', rather than 'my life'?

The idea of 'a life' is about immanence, process, virtual ity (Deleuze, 2005: 28-31) and in turn these are to do with potentiality, to a being open to becomings and transformations (Deleuze and Guattari, 1999). The idea of care and social work are transformed by this perspective from an elimination of, or dealing with, problems to a relational stance that is about how to live with (and help others to live with) problems in as creative a way as possible. Art has a place in this. As Rajchman puts it: "Deleuze came to think that artworks just are sensations connected in materials... Through affect and percept artworks hit upon something singular yet impersonal in our bodies and brains, irreducible to any pre-existent 'we' (Deleuze 2005: 9-10)". In this case the pre-existent 'we' should be understood as referring to an essentialist notion of identity, which Deleuze does not subscribe to. Art is not primarily about thought or judgement, but sensation based experience.

\section{Lives, affect, art and the potential for the new}


Virtuality as the indeterminate (yet determining) (back)ground of reality has a correlate in the notion of affect. Deleuze and Guattari (1999, p. xvi) see affect as 'a prepersonal intensity corresponding to the passage from one experiential state of the body to another'. As such that passage is marked by sensation, yet the sensation is not determined a priori, but is open to qualification (Massumi, 2002). Qualification is the process by which we interpret some experience as pleasant or unpleasant or anything more subtly in between, and this interpretation is dependent on/is in relation to a host of other experiences that may be part of our individual present and past actual life. That actual life however does partake of the potential of the new, by being also always connected to the pre personal and virtual plane. This means all lives, even 'difficult' ones are potentially creatively undetermined in the future, rather than just pathologically predetermined by the past. This shifts the focus and gives a priority to affective encounters and to affective conditions that include environmental aspects.

This links to a different understanding of health and freedom, as Duff (2014: 19) notes in Deleuzian terms: "health is advanced or promoted in the provision of new affective sensitivities and new relational capacities".

Health may, indeed, be characterised in more Deleuzian terms as a differential process of becoming reasonable, strong and free, where freedom is understood not in some totalising way synonymous with a prevailing moral order, but rather as a specific moment of rupture or transformation in which something new emerges in an active expression of creativity and invention (ibid: 17).

The role of creative practices such as art and craft activities is that they might afford the opportunity to re-configure our affective connections and qualifications. They allow the foregrounding of some aspects of one's experience, while putting others in the background, affecting therefore perception and its qualifications, with all the ramifications that might activate. This relation and interplay between foregrounding and backgrounding is what is also involved in art (Deleuze, 2004: 31). 
In Deleuzian terms 'the arts produce and generate intensity, that which directly impacts the nervous system and intensifies sensation' (Grosz, 2008: 3). This is what in my view gives them the power to reshape processes of engagement with the world. The arts in this conceptualisation are not about the production of concepts, rather they produce affects and intensities able to address problems and provocations (ibid: 1 ). While conceptualising is not their aim, they may give rise to different affects and intensities that may align or link to different ways of thinking about problems. While artistic practices are not aimed at solving problems, they may give rise to ways of living with them in terms of changing one's relation to them.

\section{Art, experience, expertise and apprenticeship}

In Deleuze's philosophy process is key. Process, in very simplistic terms, is about how something happens; how one lives in the world, how one is affected by one's context and surroundings and how one affects them, in other words it is about movements, speeds, relationality, mostly happening below the level of consciousness. Deleuze and Guattari (1999) talk about a molecular level of becoming and transformation, happening at a subtle and mostly unconscious level: “... 'learning' always takes place in and through the unconscious, thereby establishing the bond of a profound complicity between nature and mind" (Deleuze, 2004: 205). Affective expressions- a smile, a gesture, a greeting, a way of holding-may be more important than what we know, say or do. While knowledge is needed, it is not sufficient in itself: expertise needs an experiential and relational dimension, which is of enormous therapeutic value. The word 'expertise' shares an etymological root with experience and experiential, after all, and what is meant by experience is not about what is known in academic terms, but what is learnt from practice. Some things cannot easily be learnt from books, but need to be learnt by doing. This is where the notion of apprenticeship is important. For instance, it is one thing to know about challenging behaviour in theory, another to encounter it, be affected by it and learn to regulate our own affective response, the fear, frustration, anger or confusion and learn from it. The external challenge and our own response marks a profound 
encounter that involves both parties in an intense relationship with external and internal experiences. It can bring deep learning not just about the other, but also ourselves, if deeply engaged with in both directions. Emphasising this aspect in social work, education and care training more generally and not just in relation to this more extreme example would in my view be extremely useful, as would the provision of practice supervision.

To return to Deleuze's philosophy and art - Anne Sauvagnargues (2013) argues that he has created a semiotic of creativity, based on an experiential rather than phenomenol ogical approach (Aroles and McLean, 2016) and most of his work deals with art of all kinds (Sauvagnargues, 2013; Grosz, 2008). Arts and crafts involve a relation with materials, they rely on the senses, yet connect also to what is beyond the senses. To illustrate the relation of body, materials and the forces and relations beyond the senses, Deleuze (2004: 204-5) gives the example of how to think of the sea (drawing from Leibniz) and learning to swim. The difficulty of the passage that follows may show how much easier it is to learn to swim that to theorise it and may also illustrate the challenge I have in trying to communicate what is a dense, but extremely useful set of ideas. Deleuze speaks of the sea and the 'idea' of the sea as a system of differential relations, the totality of which is expressed in the real movement of the waves, and learning to swim as the conjugation "of the distinctive points of our bodies with the singular points of the objective Idea in order to form a problematic field. This conjugation determines for us a threshold of consciousness at which our real acts are adjusted to our perceptions of the real relations, thereby providing a solution to the problem" (ibid: 204-5). While not everyone can swim, it is harder to explain in words and to unpack theoretically, than it is to learn from practice. For a very humorous rendition of the limitations of an intellectual only approach to learning I recommend reading Alexander McCall-Smith's (2004) The Two and a Half Pillars of Wisdom, where academics attempt to learn to play tennis and to swim from a book, with hilarious and ultimately tragic results. 
The experiential aspect is key to Deleuze's notion of apprenticeship of living with problems (Deleuze, 2004: 204-205). In the past much vocational training was delivered through apprenticeships: in the UK this only dwindled around 1900 (Lane, 1996) and there is a current move towards re-establishing them as part of Higher Education programmes (Skills Funding Agency 2015). Medieval apprentices would live with and learn their trade from a master craftsman, apprenticeships could last from seven to 14 years. Most Medieval and Renaissance painters had their schools and apprentices often painted large parts of a canvas; Medieval Craft Guilds passed on their expertise this way. This is because organising the materials, learning to use them and creating some expression is a complex process best learnt through a physical engagement and the role modelling of someone who has mastered the encounter with the materials. That encounter sets us against not only the resistance of the materials themselves, what they can and will do and what they will not, and connects us to our own bodies, but also confronts us with our limitations, resistance and preconceptions. I have experienced first-hand the power of such activities to provoke and soothe. I do not consider myself an artist, but I dabble, I use art and crafts as therapeutic tools for myself and have even taught art for a period of my life. I was fortunate to have an artistic mother and grandparents skilled in different crafts, all practical people able to make things. I learnt to embroider when very young; I can crochet, knit, sew and have the basics of spinning and weaving. I started to crochet again recently to relieve stress and found myself having the sense that what I was actually doing was transferring the tension and twistedness of my nervous system into the twists of the crochet: as I hooked, turned and twisted the yarn, I felt my tension flow out of me and transform into a piece of usable material; my stress became productive and dissolved, at least for a while. Adult colouring books have become popular and advocated by mindfulness practitioners as a way to 'distract' service users away from stress or distress, but another way of thinking about this is to see their potential as bringing repetition to bear on difference, in other words bringing order to chaos (I understand this to be the value of my Sudoku playing habit before going to sleep and possibly the source of its popularity). On the other hand I have also tried to paint the skies I have so enjoyed 
observing after a recent house move and have been totally infuriated by my incapacity and lack of skill. To put it in Deleuzian terms, I cannot (yet) conjugate the 'Idea' of the clouds, the interplay of light, air and water, with my handling of the paint medium. I could use a period of apprenticeship to learn this.

Having said this, one must add that knowing how to use the materials is part of the discovery and making a painting one is satisfied with is also part of the pleasure. What is involved is a disciplined experiential approach of learning what you can do with what and how to do it, which can sometimes result in more than one expected. As Grosz (2008: 4) puts it: "Art enables matter to become expressive, to not just satisfy, but also to intensify - to resonate and become more than itself." To return briefly to 'difference and repetition', one of the ways we can see art's endeavour is as the expression of the differential relations of whatever we wish to present anew (rather th an represent) by using different materials. It is about a visual imagination (re)producing those relations through materials other than those of the original event or natural manifestation, involving difference for the (re)creation of the same.

I know several peoplefor whom art is a profoundly terrifying activity, it can feel humiliating and shaming. Mostly this has to do with dashed expectations of control and mastery, preconceived ideas and ambitions, bad school experiences and the sense of regression that adults can experience in trying to do something held in high social status and commercially valued on the one hand (museums and art galleries being high culture) and childish play on the other. This is a particularly big problem when we try to create art. The crafts are less problematic by being given a lower social status to art, by being less idealised and more practically oriented towards producing useful items. Yet both arts and crafts partake of an encounter with what Benjamin (2004) might term the lawfulness of materials, meaning what can and cannot be done with them, and both involve the organising and practice of processes, both technical and in excess of what is needed for pure survival. Choosing one's tools needs to relate to both task and material. Going against the grain of 
the wood will not produce enjoyment or a good result. The making of a knitted jumper is never just about warmth, but also includes design and creativity of some kind. Chairs come in all sorts of different designs, shapes and details telling us so much about those who made them, when and for what purpose as well as telling us about those whose chairs they might be or become. Marx made it the key to his idea of what makes us different from animals, though a Deleuzian view would contest this as a unique human capacity (see Grosz, 2008).

The provocativeness of arts and crafts, the challenges they pose to us through the particular qualities of different materials, is aggravated by our tendency to focus on outcomes, rather than on a process of discovery of what the material and the person might both become in the doing. My experience of teaching painting to learning disabled young people was that there was relatively little resistance, the 'self' was getting less in the way of the activity. This I believe to be a useful initial approach for people at any stage of life: to approach art as play and experimentation and offer it as such to begin with. This is not to be understood again in a hierarchically structured and judgemental way that might see it as an invitation to regression, itself a term charged with negative connotations. Rather it should be seen as a move to the source and foundation of our social and cultural life as Winnicott pointed out (1971) and in Deleuzian terms as a 'becoming-child' (Deleuze and Guattari, 1999). This is the process of finding the receptivity, youthfulness and vital ity of each stage of life, not at all a regressive notion. Rather it is a notion deeply linked to development at all ages, congruent with the earlier statement that "health is advanced or promoted in the provision of new affective sensitivities and new relational capacities". The links made between a dynamic notion of identity, open to transformation in the future and the role of art in offering the possibility for such transformation, re-framing and re-imagining one's life, offer a different ontological base to the modernist prevailing views which entails a refocusing on process and affective encounters in promoting health. 


\section{Conclusion}

A Deleuzian approach to care and social work means a promotion of non-pathologising, nonjudgemental attitudes and an emphasis on affective dimensions of practice, including art and craft activities, rather than outcome oriented practices. While this may al ready be part of what social workers do and art may have been far more important to practice in the past (England, 1986), the focus on performance and outcomes prevalent in neo liberal ma nagement practices may be relegating this to the common sense and ethical orientation of individual practitioners. This should instead be regarded as a keystone of training and practice with ontological and epistemological foundations able to fully promote the importance of artistic and craft practices as part of what might offer opportunities for creative transformation (Parr, 2005: 57-59), something that for Deleuze and Guattari (1999) is both experiential and social (Parr, 2005: 59). The fact that this way of thinking includes environmental, social and psychological aspects in a complex inter-relation allows us to think in terms of enabling environments that will also include physical settings and arrangements, social interactions and other aspects key to affective impact.

However my focus for present purposes has been on it offering the foundation for a nonjudgemental relationality based on a particular understanding of our common humanity in that all of us may experience times of 'pre-personal subjectivity', disorientation, contradictions and less than well integrated identities in both personal and professional lives. We all share this aspect of the human condition, if we accept this framework it is an ontological ground. Whether we can withstand that experience and are able to use it creatively is what matters. This does not mean we do not need knowledge and professional expertise, but that relationality, affective encounters really matter and have to be part of that expertise. It gives us a better place to start from in relating to others, a place that may acknowledge differences and give us a way of acknowledging and relating to aspects of humanity we have in common that may be less than coherent or seemingly irrational. It might make us less afraid of our own vulnerabilities, which in turn might allow us to be more open 
to learning, which involves experience (and mistakes). It may foster compassion, not in a condescending gesture towards the less fortunate, but in terms of its etymological roots: to suffer with, to share in a human condition, rather than feel somehow above it and professionally detached, while acknowledging the strain this might put on us and how sometimes we can't but defend ourselves by detaching or be in danger of becoming too identified.

Thinking this way means that by being always connected to the pre-personal, to ' $a$ life', actual life also al ways partakes of the potential of the new. This opens us to seeing even 'difficult' lives as potentially creatively undetermined in the future, rather than just pathologically predetermined by the past. Art in this conceptualisation produces affects and intensities able to connect to 'a life', to that indeterminate aspect of our existence (Grosz, 2008: 1). How we relate to the intensity and affective singul arities of others matters. Art and craft can produce encounters with that intensity, may enable both parties to work with resistances, contradictions and elicit commun ication, by giving indirect ways of expressing that which is hard to talk about.

To conclude: the potential of creative practices is to give expression to problems and provocations and potentially help to re-configure our affective connections, foregrounding some aspects of experience, while putting others in the background. This means that how we relate to those experiences, how good or bad or how important we might judge them to be may change. That change may in turn give us new possibilities. While artistic practices are not aimed at solving problems, in that this way of thinking acknowledges life itself as problematic by its very nature, they may give rise to ways of living with them. This way of thinking gives room for hope in the future, something needed by both professionals and those entrusted to their care in difficult and uncertain times.

\section{References}


Author's own (2012) Politics and affect, Subjectivity, 5, 161-179

Aroles, J. and McLean, C. (2016) Deciphering signs: An empirical apprenticeship, Ethnography 0(00) $1-18$

Bell, K. (2012) Towards a post-conventional philosophical base for social work, British Journalof Social Work, 42(3), pp. 408-23.

Benjamin, J. (2004) Beyond doer and done to: an intersubjective view of thirdness, Psychoanalytic Quarterly, LXXIII : 5-46.

Deleuze, G. (2004) Difference and Repetition, London, The Athlone Press

Deleuze, G. (2005) Pure Immanence-Essays on a Life, New York, Zone Books

Deleuze, G. and Guattari, F. (1999) A Thousand Plateaus, London, The Athlone Press.

Duff, C. (2014) Assemblages of Health (ebook), Dordrecht, Springer

England H. (1986) Social Work as Art: Making Sense for Good Practice, London: Allen and Unwin

Goffman, I. (2009) Stigma: Notes on the Management of Spoiled Identity, London, Simon and Schuster

Gray, M. and Webb, S. (2008) Social Work as Art Revisited, Int J Soc Welfare, 17: 182-193 DOI: $10.1111 / j .1468-2397.2008 .00548 . x$

Grosz, E. (2008) Chaos, Territory, Art-Deleuze and the Framing of the Earth, New York, Columbia University Press

Lane, J. (1996). Apprenticeship in England, 1600-1914, London, UCL Press Ltd Massumi, B. (2002) Parablesfor the Virtual: Movement, Affect, Sensation, Durham, NC, Duke University Press. 
McCall-Smith, A. (2004) The Two and a Half Pillars of Wisdom, Ilford, Essex, Abacus

Moxley, D. and Feen, H. (2015) Arts-Inspired Design in the Development of Helping Interventions in Social Work: Implications for the Integration of Research and Practice, British Journal of Social Work, 46 (6): 1690-1707. DOI:https://doi.org/10.1093/bjsw/bcv087

Parr, A. (2005) The Deleuze Dictionary, Edinburgh, Edinburgh University Press

Sauvagnargues, A. (2013) Deleuze and Art, Bankston A. translation, London, Bloomsbury Publishing

Scanlon, C. and Adlam, J. (2006) Housing 'unhoused minds': inter-personality disorder in the organisation?, Housing, Care and Support, Vol. 9 Iss 3 pp. 9 - 14

http://dx.doi.org/10.1108/14608790200600018 [accessed 29/09/2016]

Skills Funding Agency, (2015) Higher and degree apprenticeships - information for employers and HEls, https://www.gov.uk/government/collections/sfa-higher-and-degree-apprenticeships [accessed $9 / 12 / 16]$

Trevelyan, C. Crath, R. and Chambon, A. (2014) Promoting Critical Reflexivity through Arts-Based Media: A Case Study, British Journal of Social Work, 44, 7-26 doi:10.1093/bjsw/bcs090

Tudor, R. Maidment, J. Campbell, A. Whittaker, K. (2015) Examining the Role of Craft in PostEarthquake Recovery: Implications for Social Work Practice, British Journal of Social Work, 45 (suppl_1): 205-220 DOI:https://doi.org/10.1093/bjsw/bcv126

Winnicott, D. W. (1971) Playing and Reality, London, Routledge 
